Rhode Island College

Digital Commons @ RIC

Master's Theses, Dissertations, Graduate

Master's Theses, Dissertations, Graduate Research and Major Papers Overview Research and Major Papers

2015

\title{
Exploring Barriers to Code Status Discussions
}

Christina Marie Dickson

Rhode Island College

Follow this and additional works at: https://digitalcommons.ric.edu/etd

Part of the Other Nursing Commons

\section{Recommended Citation}

Dickson, Christina Marie, "Exploring Barriers to Code Status Discussions" (2015). Master's Theses, Dissertations, Graduate Research and Major Papers Overview. 114.

https://digitalcommons.ric.edu/etd/114

This Major Paper is brought to you for free and open access by the Master's Theses, Dissertations, Graduate Research and Major Papers at Digital Commons @ RIC. It has been accepted for inclusion in Master's Theses, Dissertations, Graduate Research and Major Papers Overview by an authorized administrator of Digital Commons @ RIC. For more information, please contact digitalcommons@ric.edu. 
EXPLORING BARRIERS TO CODE STATUS DISCUSSIONS

by

Christina Marie Dickson

A Major Paper Submitted in Partial Fulfillment

of the Requirements for the Degree of

Master of Science in Nursing

in

The School of Nursing

Rhode Island College

2015 


\section{Acknowledgements}

I would first like to thank my amazing parents for instilling the importance of education into me at such a young age and pushing me to be my very best. Thank you for being a phone call away and agreeing to ride on this rollercoaster with me for the past 3 $1 / 2$ years. Without your unconditional love, and guidance, I may not have made it through to the end. I would also like to thank my husband to be, Jason, for being my rock and loving me, even at my craziest. I love you.

I would like to thank Dr. Cynthia Padula, my first reader, Dr. Nancy Blasdell, my second reader and David Robey, my third reader. Your wisdom was most appreciated and I thank the three of you from the bottom of my heart. My hope is we can finally begin to change the way the world views death and dying.

Lastly, I would like to thank two of the greatest ladies I have ever had the pleasure of knowing. Christine Pierce and Veronica Seippel. I would never have made it through this program without the two of you by my side. Your support and encouragement goes beyond words and I am so excited for what the future holds for us. 


\begin{abstract}
It is imperative that Advanced Practice Registered Nurses (APRNs) have the skill set necessary to initiate code status discussions with people. The literature supports that healthcare providers tend to avoid the topic, for reasons that include feeling uncomfortable, not having enough time, and not wanting to take away hope. How do we break down these barriers to ensure that healthcare providers feel comfortable and prepared to have code status discussions? The purpose of this project was to explore perceived barriers encountered by the Advanced Practice Registered Nurse (APRN) student population. A survey was developed that included sections on comfort level with code status discussion, beliefs about DNR, barriers encountered in code status discussions, and two open ended questions. Findings revealed that participants overall were comfortable with having code status discussions, but were unfamiliar with the MOLST tool, a relatively new measure being used to facilitate code status discussions. Most participants believed that patients should always be informed about code status and should be asked if they would like to be a DNR. Numerous barriers were cited, the most common being unrealistic expectations and feeling uncomfortable addressing the issue of code status. More education, time and support, were cited as what would enable participants to have better conversations. Starting these discussions in the primary care office and then ensuring that this information is passed on could potentially improve outcomes. Advocating for policy changes at the institutional, state, and national levels is needed. Quality, patient-centered code status discussions are imperative in ensuring the patients are allowed to have good deaths.
\end{abstract}




\section{Table of Contents}

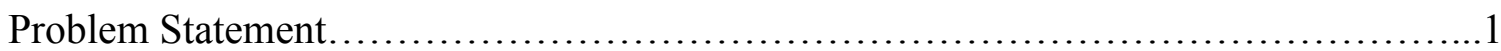

Review of the Literature.....................................................

Theoretical Framework........................................................ 14

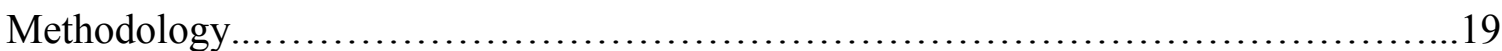

Results.................................................................23

Summary and Conclusions....................................................

Recommendations and Implications for Advanced Practice Nursing...................34

References..................................................................

Appendices..............................................................41 


\section{Exploring Barriers to Code Status Discussions}

\section{Problem Statement}

Every year, 58 million people die around the world and the vast majority of deaths occurring in developed countries happen in the hospital setting, contrary to people's wishes (Gomes \& Higginson, 2008). Cardiopulmonary resuscitation (CPR) has been documented since 1500 B.C., but was actually introduced in 1960 as a technique to prevent sudden and unexpected death and with time, it achieved universal recognition. It began to be applied to the majority of dying patients admitted to hospitals, a decision usually made independent of how sick the patient was or the prognosis associated with their illness. Cardiopulmonary resuscitation was viewed as an ineffective, last ditch effort on the part of physicians and other health care workers and as a means to show that they put their best foot forward (Ramírez-Rivera, Cánova-Díaz, \& Hunter-Mellado, 2010). An alarming majority of patients, over two-thirds, do not actually have any input into their code status decision (Ebrahim, 2007). Patients and family members often feel as though Do-Not-Resuscitate (DNR) is only discussed with the elderly, ethnic, alcohol dependent and disabled patients, instead of every single patient. It is thought that doctors

may have stereotypes of who is worth and not worth saving (Griffith, 2007). The failure of health professionals to have and follow guidelines for the use of DNR orders is becoming part of a wider concern, particularly with the growth of the older population (Calam, Far, and Andrew, 2000). Code status needs to be addressed with everyone, especially in cases where CPR is considered unsuitable.

The impending death of a patient is still seen as a shortcoming by most physicians 
(Calam et al, 2000). Patients can take a turn for the worse in a matter of minutes. Almack, Moghaddam, Pollock, \& Seymour (2012) found that most individuals will not initiate these crucial conversations because of the perceived risk of taking away hope, as well as issues associated with timing. It is hard to have conversations about end of life with patients who do not consider themselves to be dying or in need of palliative care. Many feel that discussing end of life care hinders the ability to keep a positive attitude about prognosis. Other barriers experienced by healthcare professionals include inexperience, lack of cultural awareness, unrealistic expectations, issues with predicting death, stress levels, deficiencies in communication with family and patients, lack of support, and inadequate advocacy for the patient (Almack et al., 2012). These findings speak to the issue of untrained providers not being comfortable discussing the topic of death and waiting to have these conversations until it becomes too late. When this occurs, these barriers in essence impede the duty to patients to discuss end of life issues such as code status.

Advanced practice registered nurses (APRNs) are quickly becoming primary providers for our aging population, both in the hospital and in the community. They need to be able to engage in these crucial code status conversations with patients in order to protect their wishes should they no longer be able to express them. Advanced practice registered nurses need to feel comfortable and empowered to advocate for patients and to have these conversations with families and patients so that essential information is presented and questions are answered. Having the ability to initiate these necessary conversations may also provide APRNs with the comfort of knowing they did not 
contribute to unnecessary suffering. However, this raises important questions: Does the APRN have the knowledge, skills and attitudes to competently, quickly and compassionately have a conversation to address code status? Is the APRN able to overcome barriers in order to act as an advocate for patients?

The purpose of this project was to explore the barriers that prevent the APRN student from initiating code status discussions with patients and family members.

A review of the existing literature surrounding this topic will be presented and discussed in the following section. 


\section{Review of the Literature}

The literature search was conducted using databases from the year 2000 to present, and included PubMed, CINAHL, HELIN library at RIC, and the New York Library BobCat server. Key search words were code status, resuscitation orders, physician education, medical residents and interns, nurse education, health care professionals, advanced practice registered nurses, critical care, and end of life. These terms yielded broad results, so terms such as 'physician education', 'code status discussions', 'barriers to code status discussion' and 'code status discussion knowledge' were combined. The results were fairly abundant, since this topic is constantly under scrutiny, but provided insight to a potential gap in the literature. Much research has been conducted on the topic of code status and the importance of discussions surrounding it. However, there is limited research on actual barriers to code status discussions and less related on how to break down these barriers. A review of the most relevant literature follows.

\section{History of CPR and Do Not Resuscitate Orders}

Resuscitation efforts have been documented since 1500 B.C. The ancients believed that death was a special form of sleep for an individual. During the middle Ages, resuscitation was viewed as a forbidden act against an individual. Progressing to the era of Renaissance, anyone opposed to resuscitation was challenged. During the era of Enlightenment, scholars began to dig deeper into the scientific aspect of what happened when the body died (Ekmektzoglou et al., 2012). The multiple aspects of cardiopulmonary resuscitation, such as ventilation, circulation and electricity were 
gradually identified and individuals began to understand the complex way the body responds during periods of crisis (Ekmektzoglou et al, 2012). These advancements led to the eventual development of what we know as cardiopulmonary resuscitation.

Cardiopulmonary resuscitation (CPR) was scientifically introduced in the 1960s as a technique used by healthcare professionals to prevent sudden and unexpected death in the hospital settings. It gained in popularity over time, though it did not always provide positive outcomes for patients. Gradually, society began to look at CPR from more of a patient standpoint (Payne, 2007) and questions such as 'Does that individual want to utilize all of technology, as in CPR and other life-saving means?' and 'Do they want to make a decision that considers quality of life?' began to be raised. The concept 'Do Not Resuscitate' (DNR) emerged in response. However, most individuals are not well versed on what DNR or CPR entails (Payne). Do Not Resuscitate has turned into a "slippery slope", especially with the legal and ethical implications that are now prominent in society (Payne). Code status discussions are an essential component.

\section{Need for Code Status Discussion}

Lachman (2010) explored the history of DNR and the meaning behind it. Do Not Resuscitate orders were meant to act as a way to give competent patients the ability to determine the circumstances in which they still choose life. These orders were intended to allow patients the freedom to make a decision about their own care should they not be able to at a given time. However, discussions about DNR orders usually take place between the surrogate decision makers and the physicians, because discussions between patients and providers have not occurred and patients can no longer make decisions for 
themselves (Lachman). Nurses need to have the moral courage to be more involved in having code status discussions with patients and family members, especially if the nurse feels the physician is resisting making a decision (Lachman).

Cardozo (2005) provided an expert opinion on the importance of maintaining patient autonomy in order to potentially provide patients with a greater quality of life. Communication between professionals and between professionals and patients needs to be improved. In some instances, documentation does not match discussions and technology ends up prolonging an individual's life when it is not warranted because discussions have not occurred regarding code status. The author attributes this to poor communication. Do not resuscitate orders and advanced directives need to be clarified, so that not only is the patient able to have a good death, but the family may have peace as well (Cardozo).

"The duty to provide treatment imposed on a health professional, such as district nurses, when they undertake to care for a patient does not allow them to override the wishes of a capable adult patient. A capable adult is entitled to refuse treatment even where this would lead to their death" (Griffith, 2007, p.229). Health professionals, including APRNs, need to be mindful that they should provide necessary information to assist patients and their families in making an informed decision about code status. There is a further duty to not project their opinion onto them (Griffith). Legally, the making of a lawful DNR order is the result of consultation with the patient and family and with careful consideration of the patient's situation in relation to the benefits of CPR (Griffith). Code status discussions need to occur with all types of patients, especially in cases where 
CPR is considered inappropriate. Education is imperative. Some patients and families have commented that they feel DNR is only discussed with the elderly and disabled patients instead of everyone (Griffith).

\section{Medical Professionals' Opinion on Code Status}

Giles and Moule (2004) conducted a study on nurses' attitudes about DNR code status. There was not a policy for code status and the authors wanted to see how the nurses would feel about having a policy put into place. An adapted questionnaire was administered to 78 nurses to examine attitudes toward DNR status in comparison to a new policy that was being considered. Nurses were chosen based on age, grade, years of nursing, area of nursing practice and length of nursing experience on their current ward. Eighty-four percent of the nurses felt that the next-of-kin should be involved in the decision on a DNR code status and $97 \%$ agreed that it was important to maintain patient autonomy with regard to deciding code status. The authors concluded that the nurses' attitudes were very similar to the policy that was being considered for implementation, but in order to accept this new policy, some changes were going to have to be made for it to be effective. Nurses identified that the doctors did not always use consistent language to indicate if a patient wanted to be DNR or not, which needed to be clarified for documentation purposes. Nurses also thought they should be consulted by the physician to add their input into code status on behalf of their patients.

A prospective descriptive survey was used to gather information about the perceptions of doctors and nurses on code status terminology (Wittmann-Price \& Celia, 2010). One hundred and eighty seven medical professionals, including both physicians 
and nurses in the hospital setting, completed a survey that inquired about using a new terminology, called Allow Natural Death (AND) to speak to critically ill patients. The idea was that the acronym DNR alone is enough to make people turn the other way; what would be the impact if those words were somehow made less harsh?

Eighty-three percent of nurses $(\mathrm{n}=72.21)$ said they would be highly likely $(75 \%$ of the time) and $51 \%(n=44.37)$ said they would be $100 \%$ likely to get consent if they had different terminology to use when discussing end of life with patients and families. Seventy-eight percent of physicians $(n=78)$ said they would be highly likely $(75 \%$ of the time) and 33\% ( $\mathrm{n}=33)$ would be $100 \%$ likely to get consent if they had different terminology to use. Participants thought that by using terminology that was more acceptable and comfortable, such as 'to allow natural death', they might be more inclined to initiate conversations more often. The authors commented on the need to remove dehumanization from end of life care. They noted that by using the AND terminology, families, patients, and medical professionals may have an easier time implementing these important discussions.

Ramírez-Rivera et al (2010) distributed a questionnaire to assess what the knowledge and implementation skills were of 130 internal medical residents at a Puerto Rico hospital. The study was descriptive in nature, using both qualitative and quantitative components. All of the participants stated they were familiar with the DNR protocol, but $25 \%(\mathrm{n}=34)$ rated their knowledge level as a seven or less out of 10 . Based on these results, the authors suggested that there needed to be more focus on educating newer generations of medical professionals on issues that surround DNR to 
help aid in better communication. They commented that present day training programs do not effectively educate medical residents in end of life care. Forms like the Medical Order for Sustaining Treatment (MOLST) are intended to facilitate end of life care. Aultman (2010) discussed how using the MOLST tool is making end of life discussions easier. She commented that individual's preferences go beyond just DNR or comfort measures, which prove to be confusing to patients.

\section{Medical Orders for Life-Sustaining Treatment}

The MOLST form is now being utilized in hospitals nationwide. Adapted from the Physician Order for Life Sustaining Treatment (POLST) and initially implemented in Oregon, it was then redesigned by individuals in New York State. They hoped to encourage medical care providers to have conversations with patients and families about how they would like to carry out their life, so that patients' wishes would be honored. It is a promise, from the healthcare professional, that the patient's wishes will be honored (Bomba, 2011). There is an increasing need for advanced care planning discussions and using the MOLST tool is the first step. By using it, healthcare professionals can better build trust with the patient and family and establish a relationship. "Advance care planning permits peace of mind for the individual and family by reducing uncertainty and helping to avoid confusion and conflict over care" (Bomba, 2011, p. 479). There is minimal research to date supporting the use of this form and the process it is intended to facilitate since it was recently developed and implemented. The emerging literature supports its use.

Martin \& McDonald (2014) discussed the MOLST form as a means to facilitate 
code status discussions and encourage medical providers to initiate a conversation. The authors noted that the MOLST has no value if providers do not initiate a discussion with it. They noted that just because a patient is not directly asking a provider about code status information, it does not necessarily mean that he/she does not want to discuss it. The MOLST form allows the patient to make decisions about end-of- life care in a respectable manner, as well as to choose comfort measures. This form is being introduced to hospitals statewide and is becoming the new norm for code status forms (Martin \& McDonald).

Araw, et al (2014) discussed the need for a tool to assist the elderly with code status discussions and stated that "MOLST is an ideal tool in caring for older adults at the end of life, providing concrete guidance, not only with regard to do not resuscitate (DNR) and do not intubate (DNI) orders, but also for practical approaches to daily care for the interdisciplinary team" (p.104). A tool such as this would be able to be used for not just the elderly population, but for all. Richardson (2014) commented on the importance of obtaining a MOLST, though it is not mandatory. At the present time, the form is used "for only individuals who are approaching the end stage of a serious, life-limiting illness or is in a condition of advance, chronic progressive illness" (Richardson, 2014, p. 8).

Using the MOLST tool to engage a patient and/or family in a discussion is the first step in exploring the patient beliefs and values and allows the healthcare provider to see if there is any advance directives in place for the patient. Yet, many barriers to code status discussions remain. 


\section{Barriers to Code Status Discussion}

Boyle, Miller, and Forbes-Thompson (2005) discussed how death is no longer viewed as a natural process in modern medicine. Though no research was conducted, the authors offered an important viewpoint on how Western medicine has turned the concept of death into a failure of modern medicine. Many medical professionals are uncomfortable with death and withholding or withdrawing treatment. They also lack communication skills. Medical professionals tend to over-treat due to the disease focus of medicine, unrealistic expectations of families, and a fear of litigation (Boyle et al.).

Calam et al (2000) used semi-structured, in-depth interviews with five family physicians and five family practice residents who admitted patients to a family practice teaching ward in a university-affiliated urban tertiary care hospital. Grounded theory was used to analyze the results. The barriers encountered by medical professionals with initiating code status discussions included personal discomfort, fear of damaging the relationship with the patient and family, limited time to establish trust, and difficulty managing complex family dynamic. The impending death of a patient was seen as a shortcoming by most of the physicians. The authors discussed the scarcity of role models for proper code status discussions.

Khan, Hassali, and Al-Haddad (2011) explored perceptions about barriers encountered in medical training from respondents in Penang. One hundred individuals were approached and 67 responded. Participants were given a 17-item study tool developed by the authors to explore perceptions about barriers faced in medical training thus far. The study instrument had an internal consistency of 0.58 . The results of the 
study revealed that barriers included overall communication ability at an intermediate level, difference in communication styles, lack of ability of patient to understand due to low literacy levels, and incompetency of physicians to deliver the required information for the patient. The authors concluded that the main problem stemmed from a separation between what the physician was trying to communicate and the way the patient perceived the information presented to them. They commented that communication barriers might be due to the "low level of health literacy among the patients and the inability of the physician to affectively listen to patients' views and describe the detailed information about the drug and disease" (p.255).

Almack et al (2012) discussed barriers encountered in practice including inexperience, lack of cultural awareness, unrealistic expectations, issues with predicting death, stress levels, deficiencies in communication with family and patients, lack of support, and inadequate advocacy for the patient. Conversations tend to not be initiated because of discomfort. With most things in life, if we are not comfortable doing something, we usually will not do it and this transcends to having code status discussions with patients and family members. It will simply be thrown to the wayside because it provokes feelings of discomfort and uneasiness (Domrose, 2012).

O'Hanlon, O’Connor, Peters, \& O'Connor (2013) used a 24-item questionnaire developed to survey nurses opinions and experiences regarding do not attempt resuscitation orders. They invited 251 participants and 178 completed the questionnaire. Only $24 \%$ of the nurses $(n=42)$ responded that DNAR orders were always clear and $26 \%(n=46)$ responded that they were always used effectively. Two percent $(n=3)$ of 
participants believed that physicians never make the right decision about DNAR orders; $74 \%(\mathrm{n}=131)$ responded sometimes and $24 \%(\mathrm{n}=42)$ responded always. The conclusions drawn from this study further support the notion of providers needing more education in this area.

In summary, there is an overabundance of literature related to code status and the importance of physician to nurse bedside discussions. However, no literature was identified that specifically addressed barriers to code status discussion for APRNs and how those barriers might be broken down. The purpose of this project was to explore the barriers that prevent APRNs from initiating code status discussions with patients and family members.

Next, William G. Perry's Scheme of Intellectual and Ethical Development, the framework used to guide this project, will be discussed. 


\section{Theoretical Framework}

Theories are the driving force behind nursing practice and are a guideline for decision-making and action plans. "Theory evaluation identifies a theory's degree of usefulness to guide practice, research, education, and administration" (McEwen \& Wills, 2011 , p. 90). The evaluation of theories is useful in making them applicable to nursing research and development. They may be utilized for a multitude of reasons; such as implementing an education tool-as the author of this paper is looking to do. The task becomes finding the theory that speaks to the work that needs to be accomplished and implementing it to see results. "Any theory-guided practice model will become richer through its testing in practice" (Parker \& Smith, 2010, p. 30).

William G. Perry's Scheme of Intellectual and Ethical Development theorized that individuals must move through a continuum of positions in the process of learning. Perry's model differs from other cognitive models in that he speaks of "how learners move from a dualistic (black versus white, right versus wrong) view of the world to a more realistic view. Accepting the realistic view requires the learner to adopt the notion that knowledge is not absolute, and that there is no absolute criteria or authority for deciding right or wrong. Different learners require different learning environments" (McEwen \& Wills, 2011, p. 359-360). In addition, ethics plays a role in this scheme because as noted above, the learner is going to have to find a way to distinguish within themselves, what they find to be right versus what they find to be wrong, even when their opinion differs from others. 
Perry's scheme moves through nine positions of intellectual and ethical development with each position building upon the next. Beginning with position one (basic duality), then two and three (dualism), the learner believes all knowledge to be "absolute and his/her belief systems are unquestioned and unanswered. To question authority is unthinkable" (McEwen \& Wills, 2011, p. 360). "A salient characteristic of this structure is the source of its innocence; its lack of any alternative or vantage point from which a person may observe it" (Perry, 1978, p.62). At this position, the APRN is in no place to suggest discussing code status to a superior, especially when they are a new APRN, even if they know that this conversation needs to be had.

Positions two and three allow the learner to now "accept multiple perspectives and simply seek to please the teacher" (McEwen \& Wills, 2011, p. 360). In many circumstances, new APRNs rely on others' beliefs and opinions when starting out. They have not had exposure to circumstances and time to develop their own thoughts and feelings, and find adopting others' beliefs helps to maintain the status quo. "A person may have recourse to them whenever he/she feels unprepared, resentful, alienated or overwhelmed" (Perry, 1978, p.57). In the medical field, code status discussions are usually the white elephant in the room. Everyone knows it needs to be addressed, but no one is willing to step up to the plate and talk about it, especially those individuals who have had a minimal amount of exposure to these types of conversations. It is hard to discuss matters this important when you are unsure of one's own feelings and thoughts surrounding it. 
Positions four, five, and six (relativism) allow the learner to recognize that "all knowledge is not absolute truth. There is a realization that one is responsible for defining oneself, and that the condition of one's existence is influenced by his or her own life choices" (McEwen \& Wills, 2011, p. 360). Perry calls position four "an escape through detachment" (Perry, 1978, p.107). After experiencing time in ones' profession, attitudes begin to form and an understanding of how one would like to practice is decided upon. Choices are made that may differ from those more respected, but an underlying acceptance is appreciated. Thought processes may now shift from quantity of life to an overall quality of life. Advanced Practice Registered Nurses (APRN's) may start to feel more comfortable approaching the topic of code status with those individuals known to have a poor prognosis. The APRN is now beginning to understand that death really is not a failure of modern medicine, as the literature states. Rather, it is simply another phase of life.

Positions seven, eight, and nine (commitments), the last phase as Perry denotes, is described as the "learner becoming skilled in rational processes and can commit to a system of values, beliefs, and opinions that is used to define the self" (McEwen \& Wills, 2011, p. 360). The learner now has a clear understanding of what certain concepts mean to them and the values they are now attaching to it. They are better able to practice with the skills and knowledge they have learned in a more competent and caring manner and a subsequent comfort level will increase. The dying cancer patient, whose family is pushing for more chemotherapy, will be advocated for because the APRN will have the 
knowledge and expertise to know it is time to intervene and have that uncomfortable discussion about preserving quality of life.

Ethical development, a portion of Perry's scheme, is important in helping to guide the APRN in making the best decision possible for the patient and family members. Parker and Smith (2006) stated that "ethical knowing informs us of what is right, what is our obligation, and what the nurse ought to do in any situation" (p. 26). Though this type of knowing is spoken about in terms of nursing, it can be applied to all medical professionals. A solid foundation in ethics is necessary to be able to make decisions in a person's best interest. As with any situation involving ethics, an expert panel should be available to review certain scenarios that may arise because most medical professionals are not considered experts in ethics. In terms of code status, some families are not ready to let go of loved ones and continue to prolong treatment because they feel they are buying time for their loved one. The APRN, using Perry's scheme to guide their practice, will be able to have a better understanding of the process they have gone through to now get to the point where they are comfortable having these 'uncomfortable' discussions. They will begin to see the issues that surround prolonging someone's life and will understand the obligation they have for being an advocate for their patient. The APRN will have a sense of growth, as they have worked through the stages that Perry reflects on. In the end, they will have gone from relying on others' opinions to being able to stand behind their own beliefs and be able to better advocate for the patient.

Perry's scheme served as a guide for the author's study to help to understand and appreciate that not every individual learns the same. Information must be presented to 
the learner and they must be allowed to process it in their own way and make it useful to their own practice. The concept of moving through different positions speaks to the APRNs lack of knowledge and experience in their new professional role as they are starting out. Perry's scheme allows the learner to move through these stages at his or her own pace. There is no 'black and white' way to approach a code status discussion, rather it is a skill acquired with time, practice and knowledge. The experience becomes what the learner, or APRN in this instance, makes of it.

The author believed this scheme would be beneficial for the proposed research related to what barriers exist for APRNs when discussing code status with their patients. It is important to be mindful that in order for an individual to learn, they must first pass through several positions, such as Perry's, to gain an understanding and appreciation for one's beliefs and values. This will become beneficial with code status discussions because many aspects need to be taken into consideration when addressing this sensitive topic. It is not a discussion that someone can effectively have if they have not had any prior experience or if they brush off code status discussions and wait until it is too late. By identifying the barriers that exist, the APRN can begin to move through the nine stages that Perry discusses and appreciate that this skill comes with time and practice. Not everyone comes out of school as an APRNP ready to discuss death and dying with their patients. Breaking down these barriers and allowing the APRNP to fully develop their confidence becomes key to enhancing the ability of APRN's to have crucial conversations with patients and family members about code status.

Next, the methodology will be discussed. 


\section{Methodology}

\section{Purpose}

The purpose of the proposed study was to identify barriers that are encountered by Advanced Practice Registered Nurses (APRN) students in having code status discussions with patients and family members.

\section{Design}

This research used a descriptive survey design, including both qualitative and quantitative questions.

\section{Sample and Site}

The sample included APRN students in the Rhode Island College Master of Science in nursing program. Inclusion criteria included students currently enrolled in the Master's program, including those in the NP, CNS, and CRNA option, with at least three years of acute care experience. Exclusion criteria included those with less than three years of current acute care experience and enrolled in the Public Health option. Nonprobability convenience sampling was used to recruit potential subjects. The surveys were administered at Rhode Island College in selected classrooms where APRN students were enrolled in classes during the fall 2014 semester.

\section{Measurement}

Review of the literature indicated that not one particular measurement tool was available to address the nature of the information for the purpose of this research. One area of interest was the providers' comfort level with particular code status situations. The student researcher constructed questions about provider comfort level based on the 
information derived from the literature; these questions comprise the first part of the survey, items \#1-12 (Appendix A). As reflected in the survey, comfort level with communicating with patients, families, and physicians about code status, managing patient/family dynamics, initiating code status discussions with patients, families, and physicians, discussing code status with patients, families, and physicians, using the MOLST tool and acting as an advocate for the patient are queried. A five-point Likert scale was used with $1=$ not comfortable at all and $5=$ very comfortable.

The student researcher identified that participant' beliefs about code status discussions were another area of interest. Relevant questions were identified from an article entitled "Nurses' attitudes towards Do Not Attempt Resuscitation orders" by O'Hanlon, O'Connor, Peters, \& O'Connor (2013). Permission was obtained from the author of the article to use a select number of the questions to assess the participants' beliefs about code status discussions, which are reflected in the second section of the survey. These questions were modified slightly to address the nature of the survey; they are illustrated as items 1 through 7 on the bottom of the first page of the survey. A threepoint Likert scale was used with $1=$ always, $2=$ sometimes, and $3=$ never.

Finally, barriers to code status discussions were explored. A list of barriers was identified from the literature and participants were asked to choose barriers that they had encountered in practice; see page 2 of the survey. The survey ended with two openended questions that were constructed based on the barriers found within the literature. These questions allowed the participants to provide feedback about barriers that had 
prevented them from having code status discussions and what they felt would help them have 'better' code status discussions with patients and families.

The survey was pilot tested with a small group of nurses that met the inclusion criteria in order to evaluate usability and understanding. Participants identified the survey as easy to understand and in language congruent with advanced nursing practice. No changes were made to the survey as a result of the pilot testing.

\section{Procedures}

After obtaining RIC IRB approval, faculty-teaching courses in the MSN program during fall of 2014 were contacted by email to ask permission to enter their classroom, after class had been completed, on a specified date. If faculty agreed, the student researcher attended class on the designated date and the IRB approved informational letter (Appendix B) was provided at the beginning of the encounter. The researcher provided an overview that included the study purpose and procedures, answered any questions, and then distributed the informational letter and the survey to interested participants. Students were assured that they were free to not participate and that their non-participation would not impact their class grade. The only demographic data requested was the amount of acute care experience; no names or other identifiers were included. The students placed the completed surveys in a brown manila envelope, which was stored in a locked box in the possession of the student researcher. Baked goods were distributed to all students as a thank you for participating in the study. 


\section{Data Analysis}

Descriptive statistics were performed on all study variables. Mean responses

were calculated on Likert response items and barriers were reported with frequencies and percent's. Open-ended responses were analyzed for common themes and grouped by theme. 


\section{Results}

The researcher visited five classrooms, with 62 individuals agreeing to participate in the project and complete the survey. Two subjects did not answer the majority of the questions and four subjects had less than three years of acute care experience. The data from these six subjects were not analyzed, resulting in a final sample of 56. Participants' acute care experience ranged from 2 to 32 years, with a mean of 10.26 years.

Part 1 of the Barriers to Code Status Discussions measure asked the participants to identify comfort level with various aspects of code status communication. Table 1 on the next page illustrates the responses to those questions. The range of potential responses was 1 to 5 , with $1=$ not comfortable at all, $2=$ somewhat uncomfortable, $3=$ unsure, $4=$ somewhat comfortable and $5=$ very comfortable.

Four questions ( $\# 3,7,10 \& 12$ ) had a mean response of 4.0 or greater, indicating that participants felt somewhat comfortable overall with various aspects of code status discussions. The majority of other responses $(1,2,4,5,6,8, \& 9)$ ranged from a mean of 3.0 to 4.0 , indicating that comfort level was in the mid range. Question 11, which addressed comfort with using the MOLST tool, had the lowest mean score (2.98), indicating that most people were unsure about using this tool. 
Table 1

Comfort Level with Various Aspects of Code Status Discussions

\begin{tabular}{|c|c|c|}
\hline Question \# & Question & Mean \\
\hline 1 & $\begin{array}{l}\text { Your ability to communicate effectively with patients } \\
\text { about code status discussions? }\end{array}$ & 3.96 \\
\hline 2 & $\begin{array}{l}\text { Your ability to communicate effectively with families } \\
\text { about code status discussions? }\end{array}$ & 3.65 \\
\hline 3 & $\begin{array}{l}\text { Your ability to communicate effectively with physicians } \\
\text { about patients' code status? }\end{array}$ & 4.56 \\
\hline 4 & $\begin{array}{l}\text { Your ability to manage complex patient/family } \\
\text { dynamics? }\end{array}$ & 3.56 \\
\hline 5 & Initiating code status discussions with patients? & 3.64 \\
\hline 6 & Initiating code status discussions with families? & 3.62 \\
\hline 7 & Initiating code status discussions with physicians? & 4.55 \\
\hline 8 & Discussing Do-Not-Resuscitate (DNR) with patients? & 3.75 \\
\hline 9 & Discussing Do-Not-Resuscitate (DNR) with families? & 3.69 \\
\hline 10 & Discussing Do-Not-Resuscitate (DNR) with physicians? & 4.50 \\
\hline 11 & $\begin{array}{l}\text { Using the MOLST tool to assist you with code status } \\
\text { discussions? }\end{array}$ & 2.98 \\
\hline 12 & Acting as an advocate for your patient? & 4.70 \\
\hline
\end{tabular}

Part 2 of the survey asked participants to score questions based on their beliefs about DNR. The range of potential responses was 1 to 3 , with $1=$ never, $2=$ sometimes and $3=$ always.

Table 2 on the next page describes the responses to those questions. 
Table 2

Beliefs about DNR

\begin{tabular}{|c|c|c|}
\hline $\begin{array}{c}\text { Question } \\
\#\end{array}$ & Question & Mean \\
\hline 1 & Patients should be informed about code status & 2.96 \\
\hline 2 & In general, DNR orders are written clearly & 2.16 \\
\hline 3 & In general, DNR orders are clearly discussed & 2.05 \\
\hline 4 & Physicians discuss DNR orders with you? & 1.96 \\
\hline 5 & DNR orders are effectively used & 2.09 \\
\hline 6 & $\begin{array}{l}\text { All hospitalized patients should be asked if they } \\
\text { would like to be DNR }\end{array}$ & 2.76 \\
\hline 7 & $\begin{array}{l}\text { How often do you disagree with a DNR decision, } \\
\text { made by a patient, family, or physician? }\end{array}$ & 1.87 \\
\hline
\end{tabular}

The majority of APRN students believed that patients should always be informed about code status (mean=2.96) and that all hospitalized patients should be asked if they would like to be a DNR (mean $=2.76)$. Fewer APRNs identified that physicians discussed DNR orders with them $($ mean $=1.96)$ and fewer disagreed with a DNR decision $($ mean $=1.87)$.

Part 3 of the survey asked the participants to identify from a list of eight barriers, any that they had encountered in their practice.

Table 3 on the next page describes the responses to the list of barriers. 
Table 3

Barriers to Code Status Discussions

\begin{tabular}{|l|c|}
\hline \multicolumn{1}{|c|}{ Barrier } & $\begin{array}{c}\text { Number and Percent } \\
\text { Identifying the Barrier }\end{array}$ \\
\hline Inexperience related to code status & $21(38 \%)$ \\
\hline Lack of cultural awareness & $29(52 \%)$ \\
\hline Unrealistic expectations about code status & $44(79 \%)$ \\
\hline Difficulty predicting death & $26(46 \%)$ \\
\hline $\begin{array}{l}\text { Lack of support related to having code status } \\
\text { discussion }\end{array}$ & $29(52 \%)$ \\
\hline \begin{tabular}{l} 
Difficulty in communicating about code status \\
\hline $\begin{array}{l}\text { Fear of damaging the relationship by initiating } \\
\text { code status discussions }\end{array}$
\end{tabular} & $26(46 \%)$ \\
\hline Having limited time for code status discussions & $22(39 \%)$ \\
\hline
\end{tabular}

An unrealistic expectation about code status was the most frequently identified barrier $(\mathrm{n}=44 ; 79 \%)$. Thirty-two participants $(57 \%)$ reported having limited time for code status discussions as the next most common barrier to code status discussions, 29 $(52 \%)$ identified lack of support, and $29(52 \%)$ responded lack of cultural awareness of barriers. Thirty eight percent $(n=21)$ of APRN cited inexperience related to code status as a barrier.

Participants then had the opportunity to identify any other barriers that they had encountered in their practice that were not included in the prior list. Thirty participants 
added additional barriers. The data was analyzed for commonalities in order to identify the most frequent responses from the participants.

Table 4 on the next page describes the most common responses identified.

Table 4

\section{Additional Barriers Encountered in Practice}

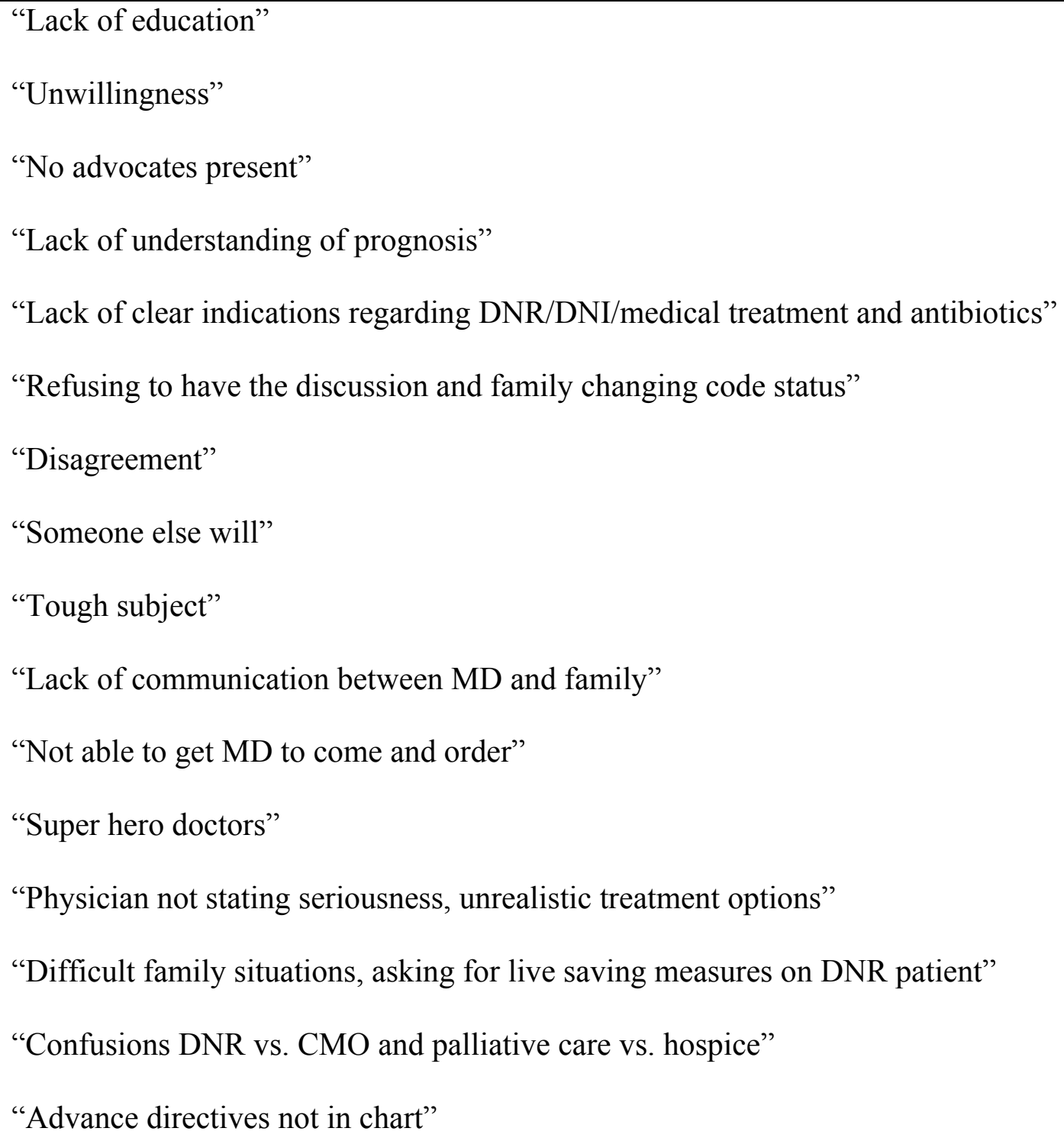


The most common theme was a lack of understanding on the part of the patient and families regarding code status (27\%), followed by family not being present to discuss code status when the patient was incapacitated (17\%) and having unrealistic expectations and an unwillingness to discuss the topic (13\%).

Part 4 of the survey included two open-end questions, with the first one asking the participant to comment on what had prevented them from having code status discussions. Table 5 describes some of the responses.

\section{Table 5}

"What Has Prevented You from Having Code Status Discussions"

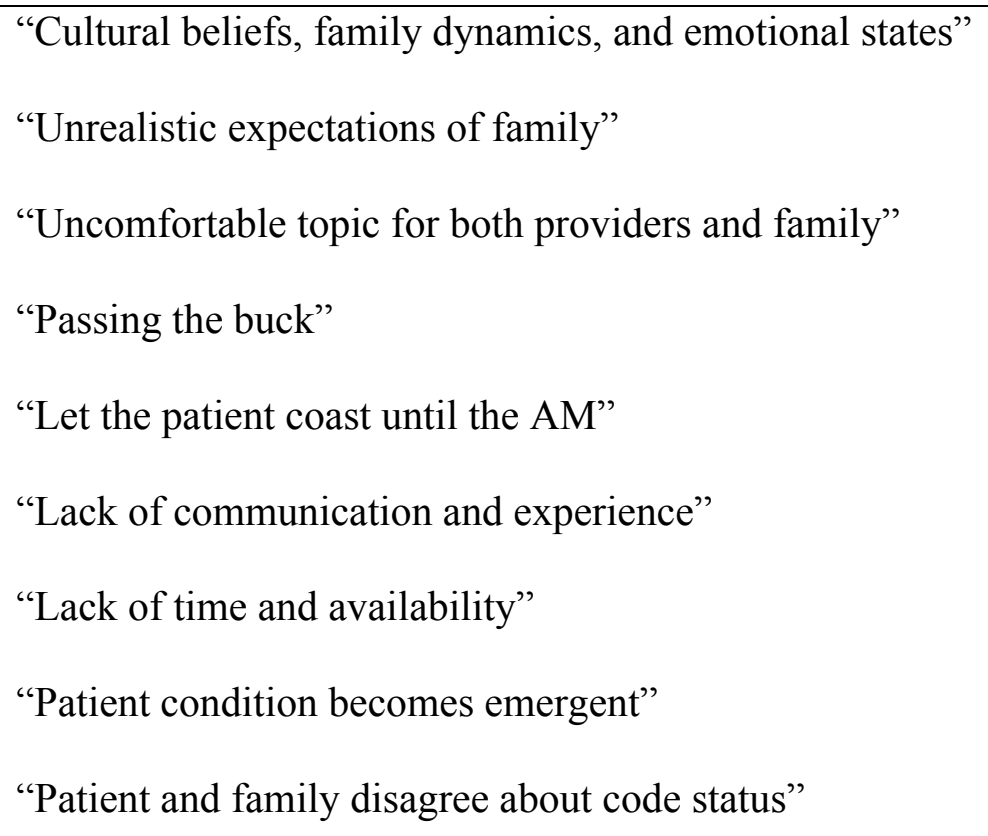


The most common themes were time (37\%), followed by unrealistic expectations (33\%), feeling uncomfortable addressing the topic (20\%), and thinking that it is the physician's responsibility to address code status (17\%).

The second question asked the participants what they feel would help them create better discussions.

Table 6 describes some of the responses.

Table 6

"What Do You Feel Would Help You to Have Better Discussions Going Forward"

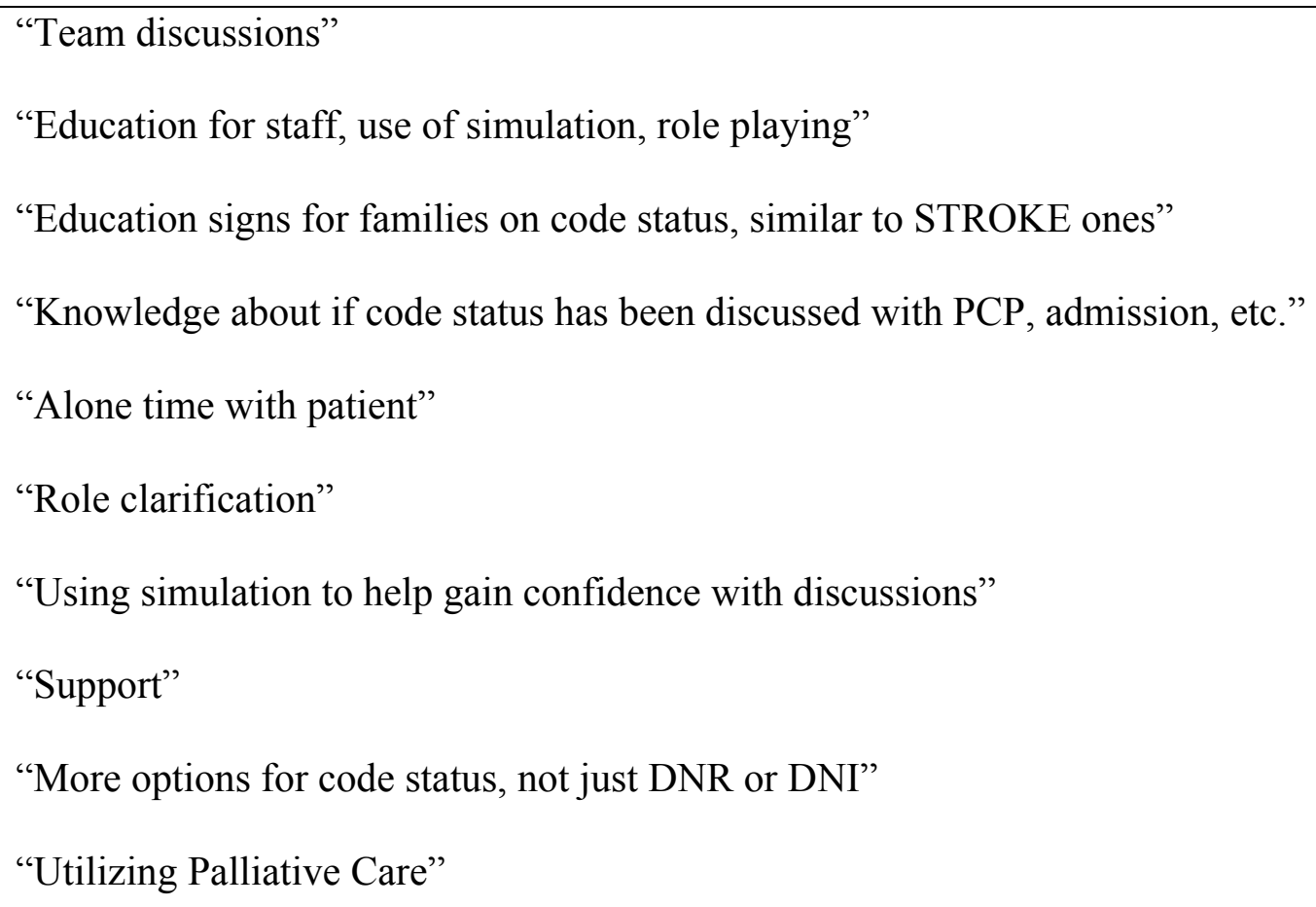

The most common themes were the need for more education for staff on how to approach the topic of code status and tools to use (50\%), knowing if the patient has had 
prior discussions with either their PCP or any other admissions regarding code status $(33 \%)$, more education for families, so they are able to make more informed choices regarding code status (30\%), and support (27\%).

Next, summary and conclusions will be addressed. 


\section{Summary \& Conclusions}

Every year, 58 million people around the world die and the vast majority of deaths occurring in developed countries happen in the hospital setting, contrary to people's wishes (Gomes \& Higginson, 2008). What is preventing individuals from dying the way they would like? Are conversations regarding code status and end of life wishes not occurring? An alarming majority of patients, over two thirds, do not actually have any input into code status decision (Ebrahim, 2007). Having the ability to initiate a code status discussion with patients and family members is an important skill that all APRNs should possess. This project sought to identify barriers that prevented APRNs from initiating these conversations with patients and family members.

The sample included 56 participants who were asked to complete a survey that included assessing comfort level with various aspects of code status discussions, beliefs about do not resuscitate, and questions regarding barriers encountered in regard to code status discussions. Participants were asked to address, via two open-ended questions, factors that prevented them from having code status discussions and what could help to facilitate these discussions in the future. Numerous themes were identified from the data. Most participants were comfortable with various aspects of code status discussions, but were unsure about utilizing the MOLST tool $(\mathrm{n}=40$; mean=2.98; range $=1-5)$. Participants were not familiar with the MOLST and its' purpose, which was surprising since the MOLST is presented in the literature as the new standard for code status discussion (Martin \& McDonald, 2014). The majority of participants $\quad(n=54$; mean= 2.96) also believed that patients should always be informed about code status and that all 
hospitalized patients should be asked if they would like to be a DNR. A smaller number of the participants $(\mathrm{n}=9$; mean $=1.96)$ identified that physicians discussed DNR orders with them and even fewer said that they disagreed with a DNR order $(\mathrm{n}=1$; mean $=1.87)$.

From a list of identified barriers, participants identified having unrealistic expectations as the biggest barrier to having code status discussions. Having limited time for discussions and a lack of support were also identified as major barriers. The least common barrier was inexperience related to code status discussions. The participants were also asked to contribute any other barriers that they had experienced in their practice that were not listed in the provided list. The most common theme that emerged was a lack of understanding on the part of the patient and family members regarding code status. Other themes included the family not being present to have the discussions when the patient was unable to, unrealistic expectations, and an overall unwillingness to discuss the topic. Participants were also asked to discuss what they thought prevented them from having code status discussions. The most common theme that emerged was time. Numerous individuals commented on the fact that there was just never enough time to actually sit down and have these needed discussions. When asked what would help them to have better conversations about code status, the most common theme that emerged was education. Numerous participants stated that more education on how to approach this subject would be beneficial, not only for staff, but for patients and families as well.

The limitations of this project included the small sample size. The focus was solely on APRN students, excluding those in the public health option and those with less than three years of experience; repeating the study with students from other study options 
as well as practicing nurses would be beneficial. Also, further research with nurses from diverse cultural backgrounds would be important, as culture is known to impact beliefs and traditions surrounding death and dying. The survey was developed from the literature and clinical experience of the writer; though the measure was pilot tested, there was no attempt to establish reliability and validity.

In conclusion, the majority of the participants stated that they were comfortable with the topic of code status, but that they needed more time, education and support in order to have better conversations. The medical culture needs to shift to a more supportive one in which patients become the center of focus and APRNs are in the perfect position to be change agents and lead the profession to this much needed change. Next, recommendations and implications for practice will be discussed. 


\section{Recommendations \& Implications for Advanced Practice Nursing}

Advance practice registered nurses (APRNs) are in a perfect position to serve not only as role models in nursing and healthcare but also as leaders of change. They have the ability to design and implement evidence-based changes in practice with staff nurses as well as physicians and other members of the inter-professional team. Advance practice nurses are uniquely positioned to bridge the barriers that surround code status discussion with staff nurses; most are experienced nurses who also, in the Licensed Independent Practitioner (LIP) role, interact with physicians on a professional, collegial level. A number of survey participants believed that doctors did not discuss code status with them; this was surprising since nurses spend the most direct time with the patient and family. Supporting nurses and advanced practice nurses to initiate these conversations could relieve some of the stress on doctors while empowering nurses and potentially improving outcomes for patients and families.

Advance practice nurses can be influential in promoting code status discussions and assuring that patients and families have a voice and a choice in the way they choose to spend the last days of their lives. Having enough time to spend with patients is always a challenge in healthcare and was identified as an important barrier by survey participants. Perhaps initiating code status discussion in primary care offices could be a solution. Ensuring that a process is in place to know when these conversations have been started and what has been agreed upon would be essential.

How do we support APRNs in having code status discussions? Support includes all players working toward common goals, which can be difficult when conflict exists; 
conflict is almost always present in crisis situations. Advance practice nurses need to be empowered to have these crucial conversations with patients, knowing they have the full support of fellow colleagues involved with their patients' care. Constant, open communication needs to occur between all the providers so that changes in patient condition are anticipated and conflicting information is not provided to patients and family members. It is crucial that the care team is able to provide not only the appropriate care, but culturally competent care as well. Physicians, staff nurses and APRNs should attend team-building workshops to work on their communication skills and to strengthen their ability to support one another.

Education and practice on ways to approach code status discussions are crucial. An interdisciplinary approach to this challenge, using simulation education, would be beneficial for health professions' students, as well as practicing professionals, including APRNs and physicians. Utilizing a simulation laboratory setting to practice having these conversations could be invaluable. Having the ability to practice these conversations in different types of scenarios would better prepare APRN students for the real world conversations that they are going to have. Simulation allows the practitioner to make mistakes and say the wrong thing without real world consequences and should be added to the curriculum of APRN, other LIP, and physicians' training programs.

Nurse practitioners and physicians need to use evidence-based measures such as the MOLST tool. As identified in this project, APRN students, who were also experienced practicing nurses, were unfamiliar with the MOLST or its use. Given the dramatic aging of the population, APRNs must be comfortable initiating these 
discussions and utilizing evidence-based measures, such as the MOLST, to facilitate code status discussions.

Healthcare institutions, particularly hospitals, need to have policies in place in regard to code status. A majority of individuals present to hospitals and have code status discussions for the very first time, which is difficult if they are in a crisis situation. It is not unusual for medical interventions to be provided to people who did not want them in the first place. At the state and national level, increased recognition of the importance of code status discussions is needed. A campaign, similar to the one used for stroke recognition, could be utilized to encourage people to talk with their healthcare provider about code status and what level and type of care they think they would like provided to them, should they no longer be able to communicate their wishes. These important pieces of information could then be translated into the individual's living will, which would ideally be available upon admissions for review.

Further research with diverse populations is needed. Simulation experiences could be formatted with diverse populations in mind, allowing APRN students to engage in discussions with individuals of different demographic backgrounds. Further research into the MOLST, as well as development of other measures and practices to facilitate code status discussions, is indicated. The literature in this area was very physician focused; research targeting APRNs and barriers to code status would be beneficial. Examining the impact of different strategies and interventions on quality of code status discussions and patient and family satisfaction is indicated. Nurses are the health professionals that spend the most intense and intimate time with patients. Advanced 
practice nurses are uniquely trained and positioned to positively impact discussions about code status and end of life. Appropriately trained APRNs could very well be the catalyst to reducing the barriers to code status discussions. 


\section{References}

Almack, K., Cox, K., Moghaddam, N., Pollock, K., \& Seymour, J. (2012). After you: Conversations between patients and healthcare professionals in planning for end of life care [Entire issue]. BMC Palliative Care, 11(15). http://dx.doi.org/10.1186/1472-684X-11-15

Araw, A.C., Araw, A.M., Pekmezaris, R., Nouryan, C.N., Sison, C., Tommasulo, B., Wolf-Klein, G.P. (2014). Medical orders for life-sustaining treatment: Is it time yet? Palliative Support Care, (2): 101-105. doi: 10.1017/S1478951512001010

Aultman, J. M. (2010). Ethics of translation: MOLST and electronic advance directives. American Journal Of Bioethics, 10(4), 30-32. doi:10.1080/15265161003633003

Bomba, P. (2011). Landmark legislation in New York affirms benefits of a two-step approach to advance care planning including MOLST: A model of shared, informed medical decision-making and honoring patient preferences for care at the end of life. Widener Law Review, 17(2), 475-500.

Boyle, D. K., Miller, P. A., \& Forbes-Thompson, S. A. (2005). Communication and endof-life care in the intensive care unit: Patient, family, and clinician outcomes [Entire issue]. Critical Care Nursing Quarterly, 28(4).

Calam, B., Far, S., \& Andrew, R. (2000). Discussions of "code status" on a family practice teaching ward: What barriers do family physicians face? [Entire issue]. Canadian Medical Association Journal, 163(10).

Cardozo, M. (2005). Critical care. What is a good death? Issues to examine in critical care. British Journal Of Nursing, 14(20), 1056. 
Domrose, C. (2012). Helps families and caregivers make the right decisions: Ultimate choices [Entire issue]. Clinical Care Specialty Guide.

Ebrahim, S. (2000). Do not resuscitate decisions: flogging dead horses or a dignified death? BMJ: British Medical Journal (International Edition), 320(7243), 1155.

Ekmektzoglou, K. A., Johnson, E. O., Syros, P., Chalkias, A., Kalambalikis, L., \& Xanthos, T. (2012). Cardiopulmonary resuscitation: A historical perspective leading up to the end of the $19^{\text {th }}$ century. Acta Medico-Historica Adriatica, 10(1), $83-100$.

Giles, H., \& Moule, P. (2004). Do not attempt resuscitation' decision-making: a study exploring the attitudes and experiences of nurses. Nursing In Critical Care, 9(3), $115-122$.

Gomes, B. \& Higginson, I.J. (2008). Where people die (1974-2030); Past trends, future projections, \& implications for care. Palliative Medicine, 22(1) 33-41.

Griffith, R. (2007). Do not attempt resuscitation orders: a review of the issues. British Journal Of Community Nursing, 12(5), 228-233.

Khan, T., Hassali, M., \& Al-Haddad, M. (2011). Patient-physician communication barrier: A pilot study evaluating patient experiences [Entire issue]. Journal of Young Pharmacists, 3(3).

Lachman, V. (2010). Do-not-resuscitate orders: Nurse's role requires moral courage. MEDSURG Nursing, 19(4), 249-252. 
Martin, E. \& McDonald, J. (2014) What is MOLST? RI Medical Journal. 1; 97(5): 44-6 Retrieved from PubMed

McEwen, M., \& Wills, E. M. (2011). Theoretical Basis for Nursing (3 ed.). New York: Lippincott, Williams, \& Wilkins.

O’Hanlon, S., O’Connor, M., Peters, C., O’Connor (2013). Nurses' attitudes towards do not attempt resuscitation orders. Clinical Nursing Studies, 1(1), 43-50.

Parker, M. E., \& Smith, M. C. (2010). Nursing theories \& nursing practice (3 ed.). Philadelphia, PA: F.A.Davis.

Payne, J. (2007). Historical perspectives on do not resuscitate orders and advance directives in patient care. Oncology Nursing Forum, 34(2), 545-546.

Perry, W.G. (1968). Forms of intellectual and ethical development in the college years: A scheme. New York: Holt, Rinehart and Winston.

Ramírez-Rivera, J., Cánova-Díaz, C., \& Hunter-Mellado, R. (2010). Knowledge and implementation of the DNR in internal medicine teaching programs. Puerto Rico Health Sciences Journal, 29(2), 96-101.

Richardson, K. (2014). POLST Legislative comparison and update. Bifocal, 36(1), 10. Wittmann-Price, R., \& Celia, L. (2010). Exploring perceptions of "do not resuscitate" and "allowing natural death" among physicians and nurses. Holistic Nursing Practice, 24(6), 333-337. doi:10.1097/HNP.0b013e3181fbb79f 


\section{APPENDIX A \\ Barriers to Code Status Discussions Survey}

This survey is intended to identify your beliefs and perceptions about barriers to code status discussions in practice. There are no right answers to these questions; answer from the perspective of your individual practice experiences.

Please read each statement carefully and circle the response that best describes your comfort level, using the following scale

$1=$ Not comfortable at all

$2=$ Somewhat uncomfortable

$3=$ Unsure

$4=$ Somewhat comfortable

$5=$ Very comfortable

How comfortable are you with:

1. Your ability to communicate effectively with patients about code status discussions?

12345

2. Your ability to communicate effectively with families about code status discussions?

12345

3. Your ability to communicate effectively with physicians about patients' code status?

12345

4. Your ability to manage complex patient/family dynamics? 12345

5. Initiating code status discussions with patients? 12345

6. Initiating code status discussions with families? 12345

7. Initiating code status discussions with physicians? 12345

8. Discussing Do-Not-Resuscitate (DNR) with patients? 12345

9. Discussing Do-Not-Resuscitate (DNR) with families? 12345

10. Discussing Do-Not-Resuscitate (DNR) with physicians? 12345

11. Using the MOLST tool to assist you with code status discussions? 12345

12. Acting as an advocate for your patient? 12345

Please read each statement carefully and choose the response that best indicates your beliefs about each.

$1=$ Always

$2=$ Sometimes

$3=$ Never

1. Patients should be informed about code status. 123

2. In general, DNR orders are written clearly. 123

3. In general, DNR orders are clearly discussed. 123

4. Physicians discuss DNR orders with you? 123

5. DNR orders are effectively used. 123

6. All hospitalized patients should be asked if they would like to be DNR. 123 
7. How often do you disagree with a DNR decision, made by a patient, family, or physician? 123

Below is a list of barriers to code status discussions that have been identified. Please put a check in the box for any barrier that you have faced in your practice

Inexperience related to code status

Lack of cultural awareness

Unrealistic expectations about code status

Difficulty predicting death

Lack of support related to having code status discussion

Difficulty in communicating about code status

Fear of damaging the relationship by initiating code status discussions

Having limited time for code status discussions

Please identify any other barriers to code status discussions that you have encountered:

Please respond to the following questions.

9. Please describe what has prevented you from having code status discussions with patients and families?

10. Please identify what would help you to have BETTER code status discussions with your patients?

Years of Acute Care Experience 


\title{
APPENDIX B IRB Informational Letter
}

\author{
Exploring Code Status Barriers
}

You are being asked to be in a research study about code status barriers encountered by APRN students. You are being asked because you are an APRN student. Please read this form and ask any questions that you have before choosing whether to be in the study. Christina Dickson, an MSN student at Rhode Island College and Dr. Cindy Padula, a professor at Rhode Island College will be conducting this study.

\section{Why this Study is Being Done (Purpose)}

We are doing this study to learn about barriers encountered with code status discussions.

\section{What You Will Have to Do (Procedures)}

If you choose to be in the study, we will ask you to read and answer some survey questions. The questions ask basic things regarding code status, issues surrounding their discussions, and any experiences you have had with code status discussions.

\section{Risks or Discomforts}

You may find that there is no right or wrong answer to some of these questions. Please use your best judgment. I think these questions would be similar to the kinds of things you talk about with families, patients, and colleagues and would be similar to issues you may encounter in practice. You can skip any questions you don't want to answer.

\section{Benefits of Being in the Study}

Being in this study will not benefit you directly.

\section{Deciding Whether to Be in the Study}

Being in the study is your choice to make. Nobody can force you to be in the study. You can choose not to be in the study, and nobody will hold it against you. You can change your mind and quit the study at any time, and you do not have to give a reason. If you decide to quit later, nobody will hold it against you.

\section{How Your Information will be Protected}

Because this is a research study, results will be summarized across all participants and shared in reports that we publish and presentations that we give. Your name will not be used in any reports. We will take several steps to protect the information you give us so that you cannot be identified. Instead of using your name, your information will be given a code number. The information will be kept in a locked office file and seen only by myself and other researchers who work with me. The only time I would have to share information from the study is if a court subpoenas it, or if you were suspected of harming yourself or others, then I would have to report it to the appropriate authorities. Also, if there are problems with the study, the records may be viewed by the Rhode Island 
College review board responsible for protecting the rights and safety of people who participate in research. The information will be kept for a minimum of three years after the study is over, after which it will be destroyed.

\section{Who to Contact}

You can ask any questions you have now. If you have any questions later, you can contact myself, Christina Dickson at Christina.dickson85@gmail.com or Dr. Padula at cpadula@ric.edu.

If you think you were treated badly in this study, have complaints, or would like to talk to someone other than the researcher about your rights or safety as a research participant, please contact Christine Marco at IRB@ric.edu, by phone at 401-456-8598.

You will be given a copy of this form to keep.

\section{Statement of Consent}

I have read and understand the information above. I am choosing to be in the study "Exploring Code Status Barriers." I can change my mind and quit at any time, and I don't have to give a reason. I have been given answers to the questions I asked, or I will contact the researcher with any questions that come up later. I am at least 18 years of age. 